\title{
Online solid phase extraction liquid chromatography tandem mass spectrometry (SPE-LC-MS/MS) method for the determination of sucralose in reclaimed and drinking waters and its photo degradation in natural waters from South Florida
}

Sudha Rani Batchu ${ }^{1,2}$, Natalia Quinete ${ }^{2}$, Venkata R Panditi ${ }^{1,2}$ and Piero R Gardinali, ${ }^{12^{*}}$

\begin{abstract}
Background: Sucralose has gained popularity as a low calorie artificial sweetener worldwide. Due to its high stability and persistence, sucralose has shown widespread occurrence in environmental waters, at concentrations that could reach up to several $\mu \mathrm{g} / \mathrm{L}$. Previous studies have used time consuming sample preparation methods (offline solid phase extraction/derivatization) or methods with rather high detection limits (direct injection) for sucralose analysis. This study described a faster and sensitive analytical method for the determination of sucralose in environmental samples.

Results: An online SPE-LC-MS/MS method was developed, being capable to quantify sucralose in 12 minutes using only $10 \mathrm{~mL}$ of sample, with method detection limits (MDLs) of $4.5 \mathrm{ng} / \mathrm{L}, 8.5 \mathrm{ng} / \mathrm{L}$ and $45 \mathrm{ng} / \mathrm{L}$ for deionized water, drinking and reclaimed waters (1:10 diluted with deionized water), respectively. Sucralose was detected in $82 \%$ of the reclaimed water samples at concentrations reaching up to $18 \mu \mathrm{g} / \mathrm{L}$. The monthly average for a period of one year was $9.1 \pm 2.9 \mu \mathrm{g} / \mathrm{L}$. The calculated mass loads per capita of sucralose discharged through WWTP effluents based on the concentrations detected in wastewaters in the U. S. is $5.0 \mathrm{mg} /$ day/person. As expected, the concentrations observed in drinking water were much lower but still relevant reaching as high as $465 \mathrm{ng} / \mathrm{L}$. In order to evaluate the stability of sucralose, photodegradation experiments were performed in natural waters. Significant photodegradation of sucralose was observed only in freshwater at $254 \mathrm{~nm}$. Minimal degradation (<20\%) was observed for all matrices under more natural conditions ( $350 \mathrm{~nm}$ or solar simulator). The only photolysis product of sucralose identified by high resolution mass spectrometry was a de-chlorinated molecule at $\mathrm{m} / \mathrm{z} 362.0535$, with molecular formula $\mathrm{C}_{12} \mathrm{H}_{20} \mathrm{Cl}_{2} \mathrm{O}_{8}$.

(Continued on next page)
\end{abstract}

\footnotetext{
* Correspondence: gardinal@fiu.edu

'Department of Chemistry and Biochemistry, Florida International University,

3000 NE 151st ST, FIU Biscayne Bay Campus, MSB-356, North Miami, FL 33181, USA

${ }^{2}$ Southeast Environmental Research Center (SERC), Florida International University, Miami, FL, USA
} 
(Continued from previous page)

Conclusions: Online SPE LC-APCI/MS/MS developed in the study was applied to more than 100 environmental samples. Sucralose was frequently detected $(>80 \%)$ indicating that the conventional treatment process employed in the sewage treatment plants is not efficient for its removal. Detection of sucralose in drinking waters suggests potential contamination of surface and ground waters sources with anthropogenic wastewater streams. Its high resistance to photodegradation, minimal sorption and high solubility indicate that sucralose could be a good tracer of anthropogenic wastewater intrusion into the environment.

Keywords: Sucralose; Artificial sweetener; Online SPE; Reclaimed waters; Drinking water; Photo degradation; Degradation products; High resolution mass spectrometry

\section{Introduction}

Artificial sweeteners are widely added to foods, drinks, personal care products and pharmaceutical formulations replacing sugar in low calories diet. One artificial sweetener that has gained popularity and has been used in over 80 countries worldwide is sucralose [1,2]. Sucralose (4-chloro-4-deoxy- $\alpha, D$-galactopyranosyl-1,6-dichloro-1,6didexoy- $\beta, D$-fructofuranoside) is a chlorinated disaccharide which originates from the non-chlorinated compound sucrose (Additional file 1: Figure S1).

After decades of use of artificial sweeteners, recent studies have documented their widespread occurrence in various environmental waters, such as wastewater, groundwater, surface water, and drinking water [2-9]. Although previous studies on sucralose have proved its safety for human consumption they suggest that sucralose it is extremely persistent, with a half-life in water of up to several years, depending on $\mathrm{pH}$ and temperature [10]. The compound is thermally stable and not extensively adsorbed or metabolized in humans resulting in the majority (98\%) being excreted unchanged. Sucralose enter the environment mainly because of incomplete removal during wastewater (conventional primary and secondary) treatment [1] and recent publications have shown that sucralose could be a valuable tracer to monitor impact of wastewaters in the environment [9].

Due to the unintended but widespread presence in the aquatic environment and the fact that long-term health effects resulting from chronic exposure to low levels of sucralose are largely unknown [6], the presence of $\mu \mathrm{gL}^{-1}$ concentrations of the sweetener in the environment has raised concern, especially since it could affect organisms feeding behaviors [11]. More alarming is the suggestion that sucralose could interfere with plant photosynthesis by shutting down $\mathrm{CO}_{2}$ uptake [11]. The ecotoxicological effects of sucralose still need to be systematically examined but initial studies with Daphnia magna and gammarids exposed to increasing concentrations of sucralose (0$500 \mu \mathrm{g} \mathrm{L}^{-1}$ ) showed that both physiology and locomotion were influenced by exposure to sucralose suggesting that sublethal effects rather than acute toxicity may be the mechanism to consider [12]. Although other studies indicated that sucralose has low toxicity and also did not bioaccumulate significantly in aquatic organisms [13-15], its persistence combined with the increasing use of this substance demands a more detailed ecotoxicological assessment [12].

The literature contains a minimal amount of research on the degradation of sucralose. Abiotic hydrolysis of sucralose does not appear to be a dominate mechanism of degradation where less than $1 \%$ of initial sucralose was shown to degrade into two chlorinated monosaccharides (1, 6-dichloro-1,6-dideoxy-D-fructose and 4-chloro-4-de oxy-D-galactose) after a 1 year incubation in a $\mathrm{pH} 3$ solution at $25^{\circ} \mathrm{C}$ [10]. Experiments at higher, more relevant $\mathrm{pH}$ (4 and 6) showed no hydrolysis [10]. The first study to examine biotic degradation of sucralose found that the compound could be degraded in soil although the specific microorganism(s) responsible for the degradation were not clearly identified [16]. Labare and Alexander found that sucralose can be mineralized in natural environments, such as lake sediments (4.4-18.8\%, 96-126 days), sewage $(23.2 \%, 123$ days), and surface waters $(1.1-4 \%$, $42-132$ days) to lesser extents than in soils (32.6-60.4\%, 20-101 days) $[17,18]$. The intermediates of soil microbial degradation of sucralose proposed by Labare and Alexander $[17,18]$ either the aldehyde or the uronic acid of sucralose, could not be detected in soil incubation experiments by Soh et al. [13]. The occurrence of such intermediates is still to be reported in environmental samples [19]. Incubation experiments with sweeteners in soils, Buerge et al. reported one of the shortest half-lives (DT50) at 9 days [20]. Previous studies showed that sucralose is not oxidized by UV light or visible light $[13,21]$. All these studies clearly suggest that sucralose is mostly biologically inert and degrades at a slow but highly variable rate under normal relevant environmental conditions.

Robust analytical methods for assessing sucralose's environmental fate are crucial. To date, artificial sweeteners have been determined by HPLC with reverse phase chromatography using different buffer systems, ion pairing reagents and specific derivatization procedures [5] and by GC-MS [2]. More recently, studies employing liquid chromatography-electrospray ionization-tandem mass spectrometry 
(LC-ESI-MS/MS) have been published for the analysis of sucralose in water samples by direct injection (higher detection limits) or offline SPE [3-6,8,22]. Nowadays the use of online SPE has shown important improvements such as higher sensitivity, analysis of smaller sample volumes, limited sample loss, no carry-over and robust and reproducible detection, while increasing sample throughput [23-27].

Although electrospray ionization is the most applied technique in LC-mass spectrometry, APCI has been shown some advantages over ESI, especially in the ionization of thermally stable polar and non-polar compounds. The ionization process associated with APCI is one of the most efficient, being considered more energetic or less soft than ESI, where gas phase reactions leading to the loss of net charge on the analyte may generate more fragment ions relative to the parent ion [28]. In fact, for certain classes of compounds that are traditionally very difficult to ionize or tend to show low sensitivity in LC-MS/MS techniques, electron capture negative APCI has provided increased sensitivity for these 'tough to ionize' compounds [24,29]. APCI has been reported to be more sensitive than ESI for triazines, phenylurea herbicides and organochlorine pesticides [24,30,31]. Another advantage is that signal suppression in ESI is significantly more intense than that occurring in APCI for several compounds in different matrices [32], where ionization suppression involves mainly changes in the droplet solution properties caused by the presence of non-volatile solutes in ESI ionization [33]. To this end, we have developed and validated a fast, reliable and straight-forward analytical method based on online solid phase extraction atmospheric chemical ionization mass spectrometry (SPE)-LC-APCI/MS/MS for the analysis of sucralose in reclaimed, surface and drinking waters from South Florida, U.S.A. This method was then used to evaluate the potential of sucralose photodegradation using multiple light sources and water matrices. To our best knowledge this is the first report to assess sucralose oxidation under environmentally relevant conditions.

\section{Experimental \\ Chemicals}

Sucralose was purchased from Sigma-Aldrich (Oakville, ON, Canada). Sucralose- d6 (98\% purity) was used as internal standard and was obtained from Santa Cruz Biotechnology Inc, (Santa Cruz, CA, USA). Optima LC/MS grade formic acid, acetonitrile and water were purchased from Fisher Scientific (Fairlawn, New Jersey, USA). Membrane filters $(0.45 \mu \mathrm{m}$ and $0.2 \mu \mathrm{m}$ pore size) were purchased from Millipore (Billerica, MA). Ultrapure water $\left(>18 \mathrm{M} \Omega \mathrm{cm}^{-1}\right.$ ) was generated from a Nanopure Infinity Ultrapure Water system. Stock solutions of $1 \mathrm{mg} / \mathrm{mL}$ were prepared in acetonitrile for both sucralose and sucralose d-6. All stock solutions were kept in the dark at $-18^{\circ} \mathrm{C}$.

\section{Reclaimed water}

"Reclaimed water can be defined as the end product of wastewater reclamation that meets water quality requirements for biodegradable materials, suspended matter and pathogens. Different applications of reclaimed water include landscape irrigation, agricultural irrigation in both food and non-food crops, ground water recharge and recreational purposes [34]. Various steps involved in producing reclaimed water from the wastewater include microfiltration through a series of membranes $(0.1$ to $10 \mu \mathrm{m})$, reverse osmosis, treatment with hydrogen peroxide followed by photolysis with UV light [35]. To date, FIU Biscayne Bay Campus receives reclaimed water from Miami-Dade North District Waste Water Treatment Facility, which has a capacity to treat $380,000 \mathrm{~m}^{3} /$ day of water. The capacity of the existing reuse system for FIU irrigation is 1.5 million gallons per day (MGD) for irrigating 40 acres of landscape $[36,37] "$.

\section{Sample collection sites}

Reclaimed water samples $(n=56)$ were collected at least twice monthly at Florida International University (FIU) Biscayne Bay Campus (North Miami, Florida, USA) from January 2011 to December 2011 except February2011, where only one sample was collected per month. All samples were taken directly from the sprinkler systems after they were flushed for at least 5 minutes. Drinking/Tap water samples $(n=43)$ were collected from residents' homes and shopping centers located in the Miami-Dade County area. After collection, all samples were immediately transported on ice to the laboratory, filtered through a $0.45 \mu \mathrm{m}$ glass fiber filter and then through a $0.2 \mu \mathrm{m}$ membrane filter to minimize any potential biodegradation. Filtered samples were stored in the dark at $-18^{\circ} \mathrm{C}$ until analysis.

Photodegradation experiments were performed using the two most common end members for treated wastewater releases, natural canal water and seawater. Canal water was collected from Tamiami Canal at its confluence with the Miami River. Seawater was taken from the shore at Bill Baggs state park at Key Biscayne, Miami, FL. Canal and seawater properties are shown in Additional file 1: Table S1. Environmental waters used to prepare the photo degradation experimental solutions were filtered twice using a 0.2micron $47 \mathrm{~mm}$ glass fiber filter to remove any particles and microorganisms and then stored in the dark at $<4^{\circ} \mathrm{C}$ until experiment was performed, typically within a week.

\section{Online preconcentration}

A Thermo Equan online SPE system was used for the determination of sucralose in reclaimed and drinking waters. An Accela 1000 was used as analytical HPLC pump and an Accela 600 was used as loading pump (Thermo Scientific, San Jose, CA, USA). The analytical separation was carried out using a Hypersil Gold PFP column $(100 \mathrm{~mm} \times 2.1 \mathrm{~mm}$, 
$1.9 \mu \mathrm{m})$ while the SPE pre-concentration column was a HyperSep Retain PEP $(20 \mathrm{~mm} \times 3.0 \mathrm{~mm}$ I.D) (Thermo Scientific, San Jose, CA, USA). Instrument control and data acquisition was performed using the software Xcalibur 2.1 (Thermo Scientific, USA). An HTC-PAL autosampler (Thermo Scientific, San Jose, CA, USA) was set to perform up to $10 \mathrm{~mL}$ injections. The automated online SPE cleanup and pre-concentration step was performed using only $10.0 \mathrm{~mL}$ of untreated water samples with little sample preparation. Two six-port switching valves were used for all analysis. Drinking and reclaimed water samples were prepared by adding $10 \mu \mathrm{L}$ of $500 \mathrm{ng} / \mathrm{mL}$ sucralose-d6 and the final volume was made up to $10.5 \mathrm{~mL}$ with the sample.

The online procedure consists of a divert valve on the mass spectrometer which is programmed by the data system to control the loading and elution of the two LC columns. In the Load Position, $10.0 \mathrm{~mL}$ of sample was injected into a $10.0 \mathrm{~mL}$ loop and then loaded onto a SPE column by the loading LC pump (Accela 600), followed by a wash step to remove interferences (flow rate $2 \mathrm{~mL} \mathrm{~min}^{-1}$ ). The target compounds were retained in the SPE column and the matrix that is not retained during the extraction process was directed to waste while simultaneously the analytical pump equilibrates the analytical column in the starting gradient conditions. After $5.3 \mathrm{~min}$, when the valve was switched to Inject Position, the solvent flow through the HyperSep Retain PEP column is reversed, and the analytes were then backflushed onto a Hypersil Gold PFP column for separation and quantitation by APCI-MS/MS. After $10 \mathrm{~min}$, the switching valve was returned to the loading position to allow the extraction column to be reequilibrated with water (A). Valve switching events as well as the gradient program are summarized in Additional file 2 for both drinking and surface waters. The samples were kept at $10^{\circ} \mathrm{C}$ in the autosampler. The total run time per sample was $12 \mathrm{~min}$.

\section{Direct injection LC-MS/MS method}

A direct injection method was used for the analysis of photodegradation samples. Separation was performed on a Hypersil Gold PFP column $(100 \mathrm{~mm} \times 2.1 \mathrm{~mm}, 1.9 \mu \mathrm{m})$ in 11 minutes with a flow rate of $250 \mu \mathrm{L} / \mathrm{min}$ using a binary gradient mobile phase consisting of acetonitrile (B) and $0.1 \%$ formic acid $(\mathrm{C})$ in water according to the following program: gradient from $10 \%$ to $90 \% \mathrm{C}$ in $6.0 \mathrm{~min}$ and held it for $2 \mathrm{~min}$, and gradient back to $10 \% \mathrm{C}$ in one min and held the gradient for $2 \mathrm{~min}$. Column effluent was diverted to waste for the first 2.2 minutes in order to flush out the salt from the samples.

\section{MS/MS detection}

In both methods analytes were detected on a TSQ Quantum Access QqQ Mass spectrometer equipped with an Atmospheric Pressure Chemical Ionization (APCI) source (Thermo Scientific, San Jose, CA, USA) operated in the negative mode. Preliminary tests on sucralose standards through direct injection into the LC/MS/MS were performed using HESI and APCI sources. The APCI source showed better sensitivity than HESI, moreover ESI and/or HESI spectrum generally contains abundant and extensive series of adducts ions with methanol and inorganic ions $[24,38]$. The APCI source was then selected and carefully optimized to produce reproducible spectra of the target compound. The optimized MS parameters were obtained by direct infusion of $10 \mu \mathrm{g} / \mathrm{mL}$ of standard solutions through a syringe pump at a flow rate of $50 \mu \mathrm{L} \mathrm{min}{ }^{-1}$. The standard solution was mixed with the mobile phase using a T-connector before being introduced into the APCI source. The APCI vaporizer temperature and capillary temperature were 350 and $300^{\circ} \mathrm{C}$ respectively, with a discharge current of $5 \mathrm{kV}$. Sheath gas and auxiliary gas $\left(\mathrm{N}_{2}\right)$ were used at a flow rate of 35 and 10 arbitrary units, respectively, and collision gas (Ar) pressure of $1.5 \mathrm{mTorr}$. The two transitions monitored for sucralose were $397 \rightarrow 361$ (CE, 13, for quantitation) and $397 \rightarrow$ 359 (collision energy CE, 12, for confirmation) and for sucralose-d6 were $403 \rightarrow 367$ (CE, 12, for quantitation) and $403 \rightarrow 365$ (CE, 15, for confirmation). Instrument control and data acquisition was performed using Xcalibur 2.1 software (Thermo Scientific, San Jose, CA, USA).

\section{UV photolysis}

Photodegradation experiments were conducted using Rayonet UV photochemical reactors (Southern New England Ultraviolet Co., Branford, CT) capable of irradiating samples at two different wavelengths $(254 \mathrm{~nm}$ and $350 \mathrm{~nm}$ ). Black light phosphor bulbs in the Rayonet UV reactor give out a spectrum from $320 \mathrm{~nm}$ to $380 \mathrm{~nm}$, with a maximum at $365 \mathrm{~nm}$. This band is comparable to the range of UVA region (315-400 nm) of sunlight and hence commonly used to predict the photodegradation of pharmaceutical compounds in solutions and in the environment [39]. UV $254 \mathrm{~nm}$ generated by mercury vapor lamps is the most widely used light source to induce photolysis of a wide variety of organic compounds and commonly used as advanced water treatment process in domestic wastewater and drinking water treatment plants. The experimental solution of sucralose was prepared by diluting the stock solution to $0.2 \mu \mathrm{g} / \mathrm{mL}$ with three types of water: reverse osmosis-deionized water (RODW), natural freshwater from the Tamiami canal $(\mathrm{CW})$ and seawater from Key Biscayne (SW). Three $30 \mathrm{ml}$ - quartz tubes were used for the kinetic experiments. The first tube filled with $30 \mathrm{ml}$ of RODW was used as blank. The control tube contained sucralose but was totally covered with aluminum foil to prevent light exposure. The third tube was left uncovered and exposed to light. All the tubes were placed on a merry-go-round to ensure uniform irradiation 
in the Rayonet UV photochemical reactor chamber. At specified time intervals, $380 \mu \mathrm{L}$ of the samples were transferred to a $2 \mathrm{~mL} \mathrm{LC}$ amber vial, and fortified with sucralose- $\mathrm{d} 6$ internal standard ( $20 \mu \mathrm{L}$ of $10 \mu \mathrm{g} / \mathrm{mL})$ to a final volume of $400 \mu \mathrm{L}$. Samples were thoroughly mixed and analyzed directly by LC-MS/MS. Degradation curves assuming first order decay were plotted as $\left[\ln \left(C_{t} / C_{0}\right)\right]$ versus time (hrs) using the Sigma Plot software v 11.0.

\section{SunTest photodegradation}

Sunlight plays an important role in determining the persistence and environmental fate of organic contaminants. However the intensity of natural sunlight depends mainly on the weather [40]. The intensity measured on sunny day differs from that on cloudy day and it also changes with latitude. The variable intensity of sunlight makes the kinetic parameters to vary constantly and greatly affects experimental reproducibility and interpretation. Hence experiments were conducted on a SunTest device, which is a surrogate of real sunlight. The spectra of natural solar spectrum and the SunTest are compared in Additional file 1: Figure S2. The wavelength distribution and the intensity of the Xenon lamp are very similar to those of natural sunlight [41]. Compared with the spectrum of real sunlight measured on a sunny day at Miami, FL, the light distribution of SunTest xenon lamp matched sunlight very well, especially in the $300 \mathrm{~nm}-400 \mathrm{~nm}$ range.

A SunTest XLS Tabletop Xenon Exposure System (ATLAS Material Testing Technology LLC, Chicago, Illinois, USA) was used to predict the degradation rates of sucralose in natural sunlight under environmental conditions. The SunTest XLS produces continuum of wavelengths from $300 \mathrm{~nm}$ to $800 \mathrm{~nm}$ by using a properly fitted Xenon lamp on the top of the exposure chamber (Additional file 1: Figure S2). The xenon lamp was used with its maximum abundance intensity $\left(750 \mathrm{~W} / \mathrm{cm}^{2}\right)$. Test solutions of sucralose $(0.2 \mu \mathrm{g} / \mathrm{mL})$ were prepared in three different water matrices i.e. RODW, CW and SW. In this part of the study, $25 \mathrm{~mL}$ of the experimental solutions were placed in three polyethylene bags (Nasco WHIRL-PAK 2 OZ.), which were previously tested to be UV transparent. Similarly to UV photolysis experiments 1 control bag was kept in the dark by covering it with aluminum foil (dark control) and one was left uncovered. One bag filled with RODW acts as blank. Bags were then floated in a water bath to keep the solution at a constant temperature $\left(25^{\circ} \mathrm{C}\right)$ when exposed under the Xenon lamp in the SunTest. The sampling interval and analytical procedures were identical as those for the Rayonet reactor experiment.

\section{Results and discussion Method development}

The initial online SPE LC-APCI-MS/MS developed for determination of sucralose produced MDLs of $2.7 \mu \mathrm{g} / \mathrm{L}$ for reclaimed waters and $0.7 \mu \mathrm{g} / \mathrm{L}$ for drinking waters using $1 \mathrm{~mL}$ sample volume. These MDLs are adequate for wastewaters but not for surface and drinking waters. Therefore, the method was further optimized for detection of sucralose in the ppt levels (ng/L) normally observed in U.S. drinking waters [6].

During the optimization process it was observed that the combination of water and formic acid was causing adverse ion suppression in the negative mode. This effect was also observed for several other compounds such as Endosulfan [24,42]. Therefore formic acid was eliminated and the mobile phase was switched to acetonitrile and water resulting in a 20 -fold increase in sensitivity. Moreover, the sample volume was increased to $10 \mathrm{~mL}$. The method was then able to detect sucralose at ng/L levels for all matrices. This is the first method to achieve these levels without the use of any modifier. When applying the methodology for tap water and reclaimed water samples, it was observed a high co-eluting interference with the analyte, which was not seen when formic acid was used (Additional file 1: Figure S3). In LC-MS water, no interferences were observed (Figure 1a). Separation of the interference peak from the analyte was performed by the use of a differential flow rate (Figure 1b, c). Typical chromatograms of sucralose in LC-MS water, tap water and reclaimed water can be seen in Figure 1.

\section{Method performance- online SPE-LC-MS/MS}

The online SPE LC/MS/MS method for waters samples was validated in terms of specificity, linearity, limit of detection, matrix recoveries and inter-day precision of the technique.

The chlorine-isotopic pattern for a molecule containing three chlorine atoms such as sucralose results in four spectral peaks that differ in mass by $2 \mathrm{Da}$. The specific chlorine-isotopic pattern of the sucralose molecule was observed (m/z 395, 397, 399 and 401). The most abundant ion that was capable of giving a product ion spectrum was chosen ( $\mathrm{m} / \mathrm{z}$ 397). Two SRM transitions were monitored for accurate identification and quantification of sucralose.

An 8 point calibration was prepared by spiking varying levels of sucralose working standard solution in LC/MS grade water in the concentration range of $10 \mathrm{ng} / \mathrm{L}$ to $2000 \mathrm{ng} / \mathrm{L}$. Calibration curves were built with the relative response ratio (area of sucralose divided by area of sucralose-d6) as a function of the analyte concentration. Linear response was observed in all cases $\left(R^{2}>0.99\right)$.

Method detection limit (MDL) was calculated from the standard deviation of seven spiked reclaimed and drinking water samples. Standard deviation of seven replicates was multiplied by the student $t$ value at the $99 \%$ confidence interval (six degrees of freedom, $t$ value, 3.143), according to procedures outlined by the US-EPA [43]. The matrix was spiked $(\mathrm{n}=7)$ at $50 \mathrm{ng} / \mathrm{L}, 100 \mathrm{ng} / \mathrm{L}$ and $200 \mathrm{ng} / \mathrm{L}$ with 


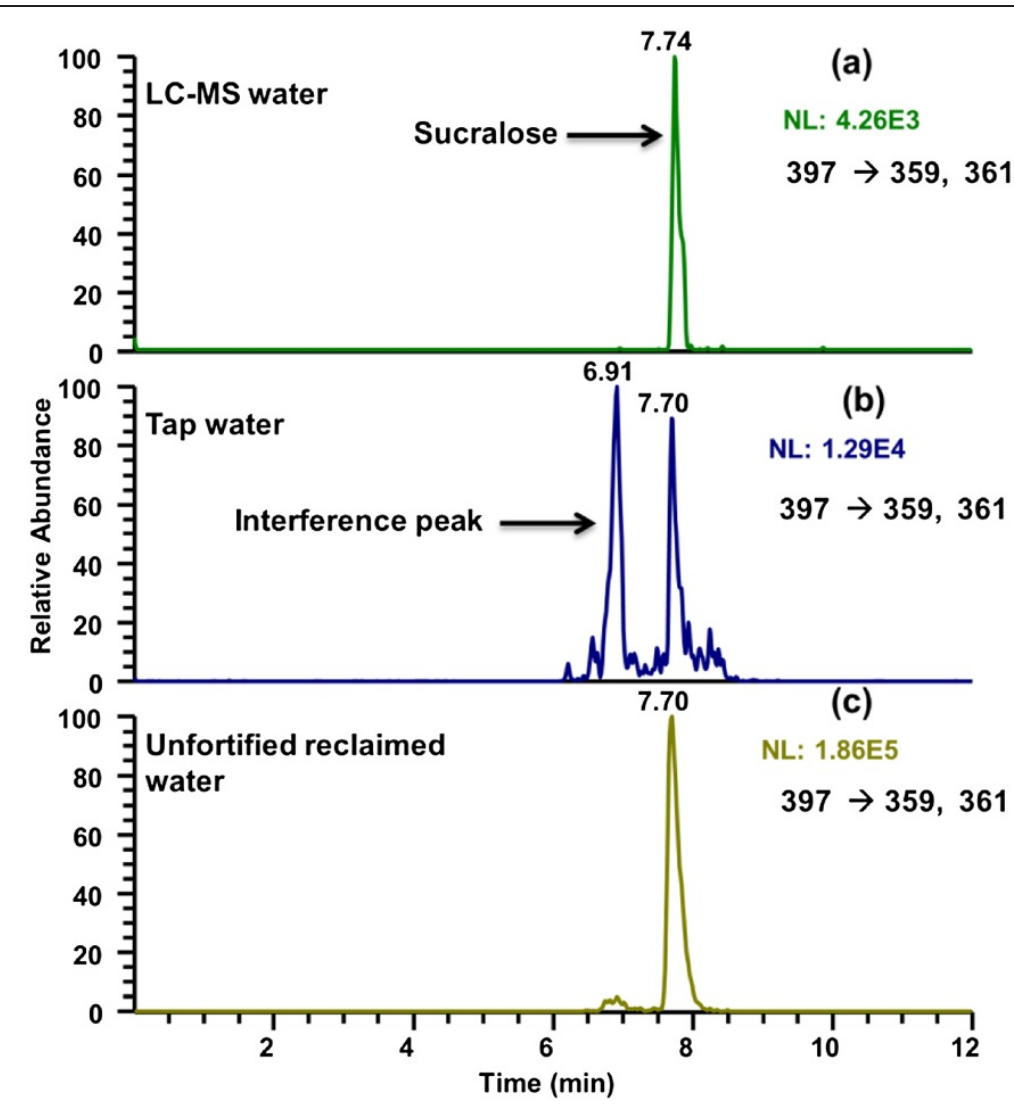

Figure 1 LC-MS/MS chromatograms of sucralose in LC-MS, tap and reclaimed water. a) LC-MS water fortified with sucralose at $100 \mathrm{ng} / \mathrm{L}$ b) unfortified tap water with a positive detection of sucralose $\mathbf{c}$ ) unfortified reclaimed water with a positive detection of sucralose.

the resulting MDLs of $4.5 \mathrm{ng} / \mathrm{L}, 8.5 \mathrm{ng} / \mathrm{L}$ and $45 \mathrm{ng} / \mathrm{L}$ in deionized water, drinking and 1:10 diluted reclaimed waters, respectively. Using this method, the MDL for the determination of sucralose in reclaimed waters improved by 6-fold. Matrix matched recoveries $(\mathrm{n}=5)$ were assessed by spiking drinking and reclaimed and water at $50 \mathrm{ng} / \mathrm{L}$ and 200 ng/L, respectively. Because real sample matrices may contain target analytes, non-spiked samples were also analyzed and the concentration found was subtracted from the spiked sample concentration. Recoveries ranged from 91 to $108 \%$ (96.7 \pm 5.27$), 85$ to $107 \%(96.2 \pm 10.9)$ and 85 to $113(97 \pm 9.7)$ in deionized water, drinking and reclaimed waters, respectively.

For a repeatability study of the LC-MS method, duplicates and replicate determinations of spiked standard mixture were carried out on the same day (intra-day analysis) and on different days (inter-day analysis). The calculated relative standard deviation (RSD) ranged from 3 to 13\% and 9 to $12 \%$ for intra-days and the inter-days in drinking water and reclaimed water, respectively.

Previous studies using offline sample preparation in surface water, drinking water, groundwater and sewage effluents reported MDLs in the range of $10 \mathrm{ng} / \mathrm{L}$ to $25 \mu \mathrm{g} / \mathrm{L}$ $[3-6,8,9,22]$, which are consistent with the present study.
Heeb et al. and Neset et al. have previously reported an online SPE LC-MS/MS determination of sucralose in wastewater, surface and drinking water; however presenting higher detection limits [26] or similar detection with larger volume of sample (20 mL) [25].

\section{Applicability of the method to environmental samples}

The developed online-SPE-LC-MS/MS methods were applied for the analysis of reclaimed water $(\mathrm{n}=56)$ and drinking water samples $(n=43)$. Concentrations below MDL were considered as not detected for the purpose of average calculation. Average concentrations and frequency of detection of sucralose in reclaimed water are presented in Table 1. Sucralose was detected in $82 \%$ of the reclaimed water samples with concentrations ranging from $4.1 \mu \mathrm{g} / \mathrm{L}$ to $18 \mu \mathrm{g} / \mathrm{L}$. The monthly average concentration was $9.1 \pm$ $2.9 \mu \mathrm{g} / \mathrm{L}$. The concentrations found in reclaimed water are comparable with previously published levels of sucralose in wastewater $[8,22]$ and at least 10 times higher than concentrations found in surface and groundwaters $[3-6,8,9]$. Based on the results obtained, month wise distribution of sucralose in reclaimed water was uniform; with no observed temporal trend and statistically difference between the wet season (April to October) and the dry season (November 
Table 1 Average concentration and frequency of detection of sucralose in reclaimed water samples

\begin{tabular}{lccc}
\hline Month & $\begin{array}{c}\text { Samples/ } \\
\text { month }\end{array}$ & $\begin{array}{c}\text { Frequency of } \\
\text { detection }(\%)\end{array}$ & $\begin{array}{c}\text { Monthly } \\
\text { averages }(\boldsymbol{\mu g} / \mathbf{L})\end{array}$ \\
\hline Jan-11 & 5 & 80 & $8.00 \pm 3.44$ \\
Feb-11 & 1 & 100 & 10.19 \\
Mar-11 & 8 & 88 & $9.63 \pm 4.05$ \\
Apr-11 & 4 & 100 & $6.96 \pm 1.18$ \\
May-11 & 8 & 100 & $9.32 \pm 2.85$ \\
Jun-11 & 9 & 89 & $8.53 \pm 2.02$ \\
Jul-11 & 6 & 33 & $5.89 \pm 2.47$ \\
Aug-11 & 4 & 75 & $10.65 \pm 6.35$ \\
Sep-11 & 2 & 50 & $12.08 \pm 1.98$ \\
Oct-11 & 2 & 100 & $9.42 \pm 1.16$ \\
Nov-11 & 4 & 100 & $10.09 \pm 1.34$ \\
Dec-11 & 3 & 67 & $8.92 \pm 2.75$ \\
\hline
\end{tabular}

to March) as seen in Figure 2. This result indicates that conventional Wastewater Treatment Plants (WWTP) are not efficient in removing sucralose. In fact, previous study by Brorstrom-Lunden et al. reported removal efficiency $<10 \%$ for sucralose in corresponding wastewater samples [1]. The chlorinated structure of the sucralose seems to be resistant to microbial degradation even in the mixed media of a sewage treatment facility, which explains its persistence through wastewater treatment processes in municipal plants [13,21]. High consumption of sucralose in recent years along with its high persistence might explain the high concentrations observed in reclaimed water. Mass loadings (mg/day) of sucralose was calculated by multiplying its average concentration and daily flow rate of the STP effluent during the sampling period (380 $000 \mathrm{~m}^{3} /$ day). Based on the serving population of Miami Dade North District [44] the mass load per capita of sucralose was $4.37 \mathrm{mg} /$ person/day, which is in good agreement with the U. S. average.

There is a growing concern related to the artificial sweetener sucralose in the United States and Canada. Sucralose has become the most detected unregulated chemical and artificial sweetener in wastewater, surface water and groundwater samples [19].

A worldwide comparison of the occurrence of sucralose in STPs and wastewaters is presented in Table 2 and the mass load per capita in the different countries were estimated [1,4,8,9,20-22,25,45-49]. The average effluent daily flow for China and European Union (EU) was calculated based on the general guideline suggested by Imhoff (1985), which estimates that $200 \mathrm{~L}$ of waste is produced per capita $[26,50,51]$. The estimated mass load per capita (mg/person/day) was high for U.S.A (5.0), moderate for the EU (2.1) and very low for China (0.37). The higher value observed for U.S. can be explained based on higher consumption of sucralose and its early introduction into market (1998) compared to other countries (Switzerland: 2005; Sweden: 2004; Germany: 2005; China: 2009) [19]. The mass load per capita on a global scale (2.1) was calculated similarly and is comparable to EU and lower than US.

The drinking water samples were collected from areas served by three major drinking water treatment plants in

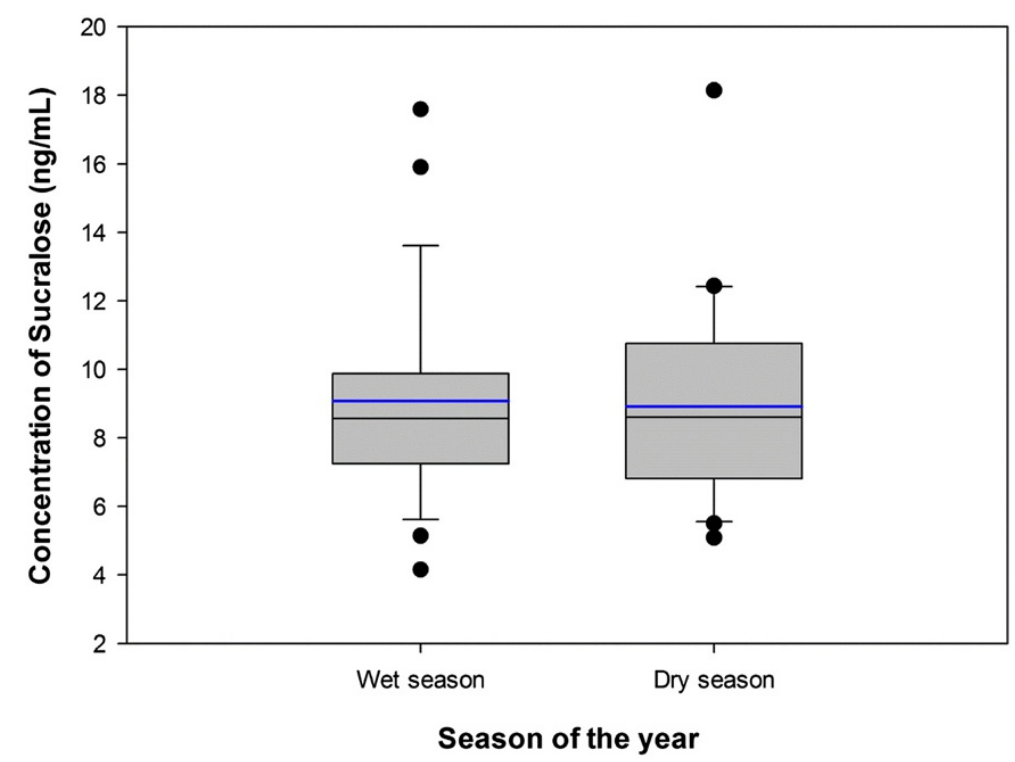

Figure 2 Distribution of sucralose in reclaimed waters in various seasons. The boundaries of box plot cover $25^{\text {th }}-75^{\text {th }}$ percentile, the center line indicates median of the sample population, error bars (whiskers) above and below the box refer to $90^{\text {th }}$ and $10^{\text {th }}$ percentiles. The blue line in each box plot indicates mean of the sample population. 


\begin{tabular}{|c|c|c|}
\hline References & $\begin{array}{l}\text { Average concentration } \\
\text { detected (ng/L) }\end{array}$ & Country \\
\hline Bronstrom-Lunden et al. 2008 & 3500 & Sweden \\
\hline Bronstrom-Lunden et al. 2008 & 4900 & Sweden \\
\hline Neset et al. 2010 & 2400 & Sweden \\
\hline Buerge et al. 2009 & 4470 & Switzerland \\
\hline Scheurer et al. 2009 & 800 & Germany \\
\hline Torres et al. 2011 & 2800 & USA \\
\hline Ordonez et al. 2012 & 49600 & Spain \\
\hline Oppenheimer et al. 2011 & 27000 & USA \\
\hline Scheurer et al. 2011 & 18000 & Germany \\
\hline Morlock et al. 2011 & 6449 & Germany \\
\hline Minten et al. 2010 & 11000 & Sweden \\
\hline Berset and Ochsenbein 2012 & 3641 & Switzerland \\
\hline Gan et al. 2013 & 1850 & China \\
\hline Current study & 9100 & USA \\
\hline Average of all studies & 10394 & \\
\hline
\end{tabular}

Miami-Dade, Hialeah and John E. Preston plant $(\mathrm{n}=24)$, Alexander Orr Jr. plant $(\mathrm{n}=14)$ and South Dade water supply system $(n=5)$. The Hialeah and John E. Preston plant serves most Miami-Dade residents living between the Miami-Dade-Broward County line and SW $8{ }^{\text {th }}$ Street. The Alexander Orr, Jr. water treatment plant, serves most County residents living between SW $8^{\text {th }}$ Street and SW $264^{\text {th }}$ Street. The other drinking water treatment plant is South Dade Water Supply System, which is comprised of five smaller water treatment plants that serve residents south of SW $264^{\text {th }}$ Street in the unincorporated areas of the County [52]. The most commonly used treatment processes include filtration, flocculation and sedimentation, and disinfection. Some treatment plants also use ion exchange and adsorption. However, the exact treatment process employed in each drinking water treatment plant is not readily available. The high concentrations of sucralose in reclaimed water could be an indication that filtration by activated charcoal is not employed by these treatment plants; since previous literature showed that sucralose was effectively removed by granular activated carbon [53]. Spatial distribution of sucralose concentration in various drinking water sample locations are shown in Figure 3, with different colors ranging from white $(<\mathrm{MDL})$ to red (>250 ng/L). Sucralose was frequently detected $(88 \%)$ in drinking water samples with an average concentration of $111 \pm 95 \mathrm{ng} / \mathrm{L}$. The highest concentration observed in drinking water was $465 \mathrm{ng} / \mathrm{L}$. No specific trend was observed between the concentration of sucralose in drinking waters and sampling location. Furthermore, means of Hialeah and John E. Preston plant samples and The
Alexander Orr, Jr. plant samples were compared using a $t$-test and results indicated that the means of the two drinking water treatment plants were not statistically different $(\mathrm{P}=0.142)$. Thus the source of variation in the concentration of sucralose among samples might be caused by the time of sample collection, residence time of the waters before distribution in drinking water treatment plant and most likely be by point sources of contamination.

Levels of sucralose in drinking water samples were similar to surface and groundwater in Europe $[3,4,6,8]$. Recent reports on U.S. ground and drinking waters $[5,6]$ showed concentration of sucralose in the $\mu \mathrm{g} / \mathrm{L}$ range, relatively higher than those reported in Europe and in the present study. For results obtained in U.S. waters, the concentrations reported here in drinking water samples (up to $465 \mathrm{ng} / \mathrm{L}$ ) were lower than in surface water (up to $10,000 \mathrm{ng} / \mathrm{L}$ ), drinking water (up to $2400 \mathrm{ng} / \mathrm{L}$ ) and groundwater (up to $2400 \mathrm{ng} / \mathrm{L}$ ) from previous studies $[2,5,6,9]$. These results suggest that levels of sucralose found in drinking and ground waters are comparable to surface water, demonstrating that this compound can be of great concern even for Drinking water Treatment Plants (DWTPs) with groundwater sources.

The occurrence of sucralose in groundwater and therefore drinking water would likely be an effect of surface water, contaminated with a nearby WWTP, being drawn into alluvial wells [5]. Therefore, it is reasonable to expect that human exposure to sucralose through tap water consumption may be widespread in the U.S.

\section{Photodegradation study of sucralose}

The photolysis decay curves of sucralose at UV $254 \mathrm{~nm}$, UV $350 \mathrm{~nm}$ and SunTest are shown in Figure 4 and the kinetic parameters obtained are shown in Table 3. Results clearly indicate that in all light sources, the extent of sucralose degradation is mainly dependent on the type of matrix used i.e. highest rate in RODW and lowest in salt water. In the most energetic light source used in the study (UV $254 \mathrm{~nm}$ ) no degradation was seen in SW (Figure 4a). Similar results were observed by Torres et al. [21] i.e. minimal degradation $(<8 \%)$ of sucralose in phosphate buffer was seen within 24 hours of exposure under UV $254 \mathrm{~nm}$. Pronounced stability of sucralose was also evident in the UV treatment of wastewaters [21], where no sucralose degraded even after $24 \mathrm{hrs}$ at $254 \mathrm{~nm}$. At UV $350 \mathrm{~nm}$ and in Sun Test (Intensity: $750 \mathrm{~W} / \mathrm{cm}^{2}$ ), sucralose was persistent to photolysis in both natural water matrices (SW and CW). Soh et al. reported that no degradation was seen for $1 \mu \mathrm{M}$ of sucralose exposed to UV 254 and 320-380 nm for 5 hours [13]. After one month of continuous irradiation only $<16 \%$ degraded indicating that sucralose will be extremely persistent under natural conditions (Figure $4 b, c$ ). Predicted kinetic parameters are shown in Table 3 and were 


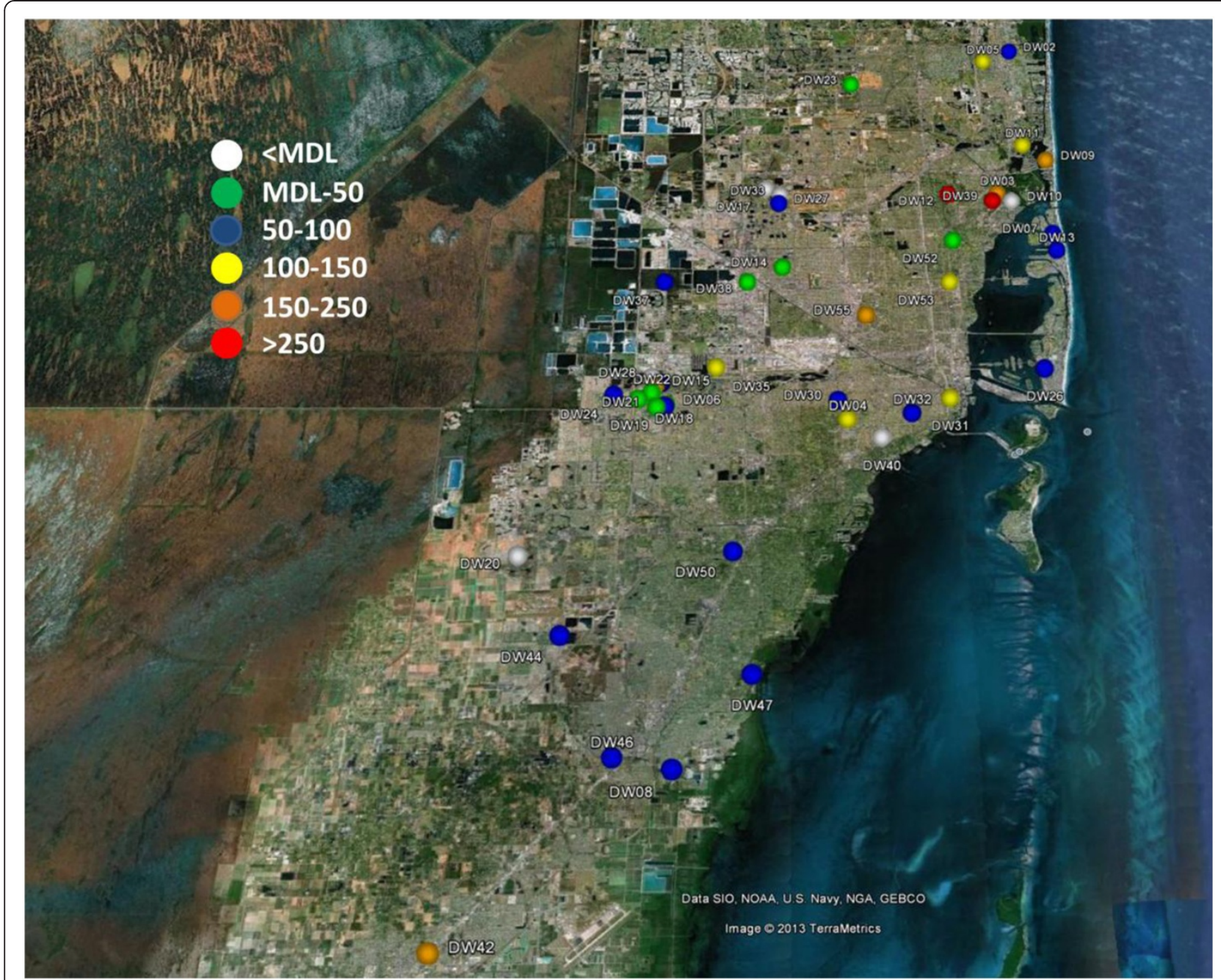

Figure 3 Distribution of sucralose in Miami-Dade County drinking waters.

calculated based on the regression equation obtained from kinetic plots.

\section{Identification of photolysis products}

Kinetic photo degradation experiments showed that sucralose can be significantly degraded $\left(\mathrm{t}_{1 / 2}=5.3 \mathrm{hrs}\right.$ for RODW) when irradiated at $254 \mathrm{~nm}$. Because of that, those conditions were used to identify major degradation products. Identification of photodegradation products was carried out using high resolution mass spectrometry. A $5 \mu \mathrm{g} / \mathrm{mL}$ solution of sucralose was prepared in two different water matrices, RODW and SW and the spiked solutions along with blank and dark control were irradiated under $254 \mathrm{~nm}$ for one week and were analyzed by LC-MS/MS. Separation of the analytes was carried out on the same analytical column (Hypersil Gold PFP column) using a binary gradient mobile phase consisting of acetonitrile (B) and $0.1 \%$ formic acid (C) in water according to the following program: $100 \% \mathrm{C}$ for the first min, gradient from $0 \%$ to $10 \%$ B in $2.0 \mathrm{~min}$, then to $90 \%$ in $7.0 \mathrm{~min}$, held it for $1 \mathrm{~min}$, and returned back to $100 \% \mathrm{C}$ in one min and held the gradient for $2 \mathrm{~min}$. Samples were analyzed by direct injection of $20 \mu \mathrm{L}$ of the irradiated solutions.

Quantitation was performed on a QExactive mass spectrometer (Thermo Scientific, San Jose, CA, USA) equipped with a APCI source operating in the negative ionization mode, using the following parameters: sheath gas flow: 35 arbitrary units; auxiliary gas flow: 10 arbitrary units; discharge voltage: $5 \mathrm{v}$; capillary temperature: $300^{\circ} \mathrm{C}$; $\mathrm{S}$ lens RF level: 90 ; vaporizer temperature: $350^{\circ} \mathrm{C}$. Accurate mass spectra were recorded in Full scan in the range 100 to $500 \mathrm{~m} / \mathrm{z}$ at a resolution of 70,000 . The calculation of exact masses from elemental compositions was carried out using ChemDraw ultra 8.0. High resolution extracted ion chromatograms of the sucralose and its potential photo transformation products were obtained by processing the full scan data using Metworks 1.3 software (Thermo Scientific, San Jose, CA) with a 5 ppm mass tolerance. A signal, 

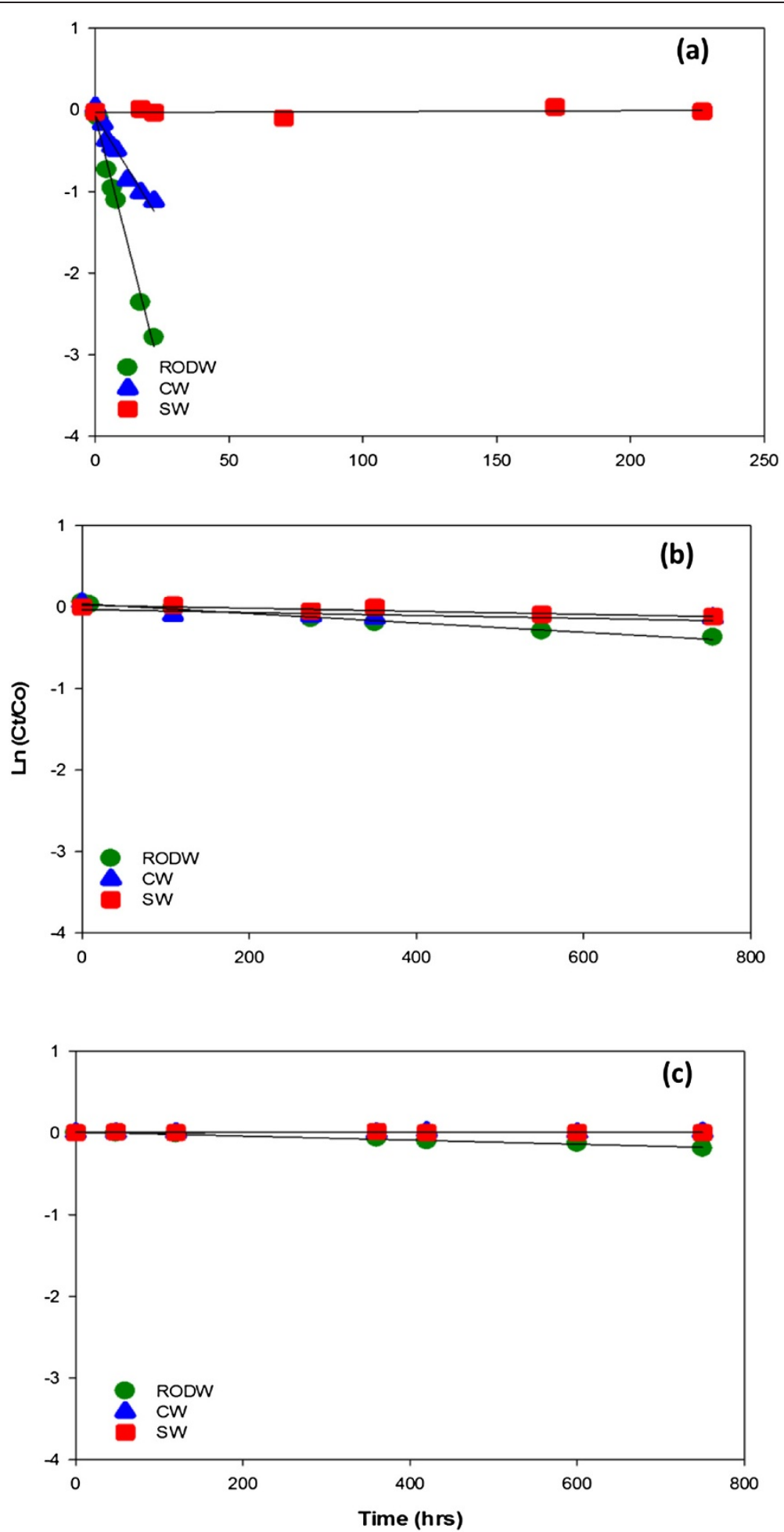

Figure 4 Kinetic profile of sucralose in various light sources. a) UV $254 \mathrm{~nm}$ light source b) UV $350 \mathrm{~nm}$ light source c) Sun Test.

increasing with irradiation dose, was found at $4.4 \mathrm{~min}$ (0.7 min earlier than the parent molecule), with a $\mathrm{m} / \mathrm{z}$ $361.0463\left(\mathrm{C}_{12} \mathrm{H}_{19} \mathrm{Cl}_{2} \mathrm{O}_{8^{-}},-0.4 \mathrm{ppm}\right)$ corresponding to the dechlorinated sucralose. HRMS spectra of this peak showed characteristic chlorine isotopic pattern for 2 chlorines i.e. $\mathrm{m} / \mathrm{z}$ 361.0463, 363.0433 and 365.0396 with 100, 63 and $10 \%$ relative abundance, respectively as seen in Figure 5. Similar to sucralose, the photolysis product also produced 
Table 3 Kinetic parameters of photodegradation experiments

\begin{tabular}{lccccc}
\hline Light source & Matrix & $\mathbf{k}\left(\mathbf{h}^{\mathbf{- 1}}\right)$ & $\mathbf{r}^{\mathbf{2}}$ & $\mathbf{t}_{\mathbf{1 / 2}} \mathbf{( h )}$ & \% degradation after a month \\
\hline UV 254 nm & RODW & 0.1290 & 0.991 & 5.37 & 100 \\
UV 254 nm & CW & 0.0530 & 0.948 & 13.1 & 100 \\
UV 254 nm & SW & 0.0001 & 0.053 & $>200$ & 0 \\
UV $350 \mathrm{~nm}$ & RODW & 0.0006 & 0.984 & 1155 & 33 \\
UV 350 nm & CW & 0.0002 & 0.464 & $>750$ & 16 \\
UV 350 nm & SW & 0.0002 & 0.818 & $>750$ & 12 \\
SunTest & RODW & 0.0003 & 0.979 & 2310 & 18 \\
SunTest & CW & 0.0000 & 0.218 & NA & 0 \\
SunTest & SW & 0.0000 & 0.021 & NA & 0 \\
\hline
\end{tabular}

a formate adduct ( $\mathrm{m} / \mathrm{z}$ 407.0518) with similar isotopic pattern as the parent molecule. A possible structure for sucralose degradation product (by the loss of chlorine from the six membered ring) was proposed (not shown here) based on the full scan HRMS.
Targeted MS/MS experiments were performed on both sucralose and its photolysis product at 35,000 resolution using normalized collision energy (\% NCE) ranging from 10-100. When operated in negative ion mode, even at the lowest NCE used (10\%), excessive fragmentation

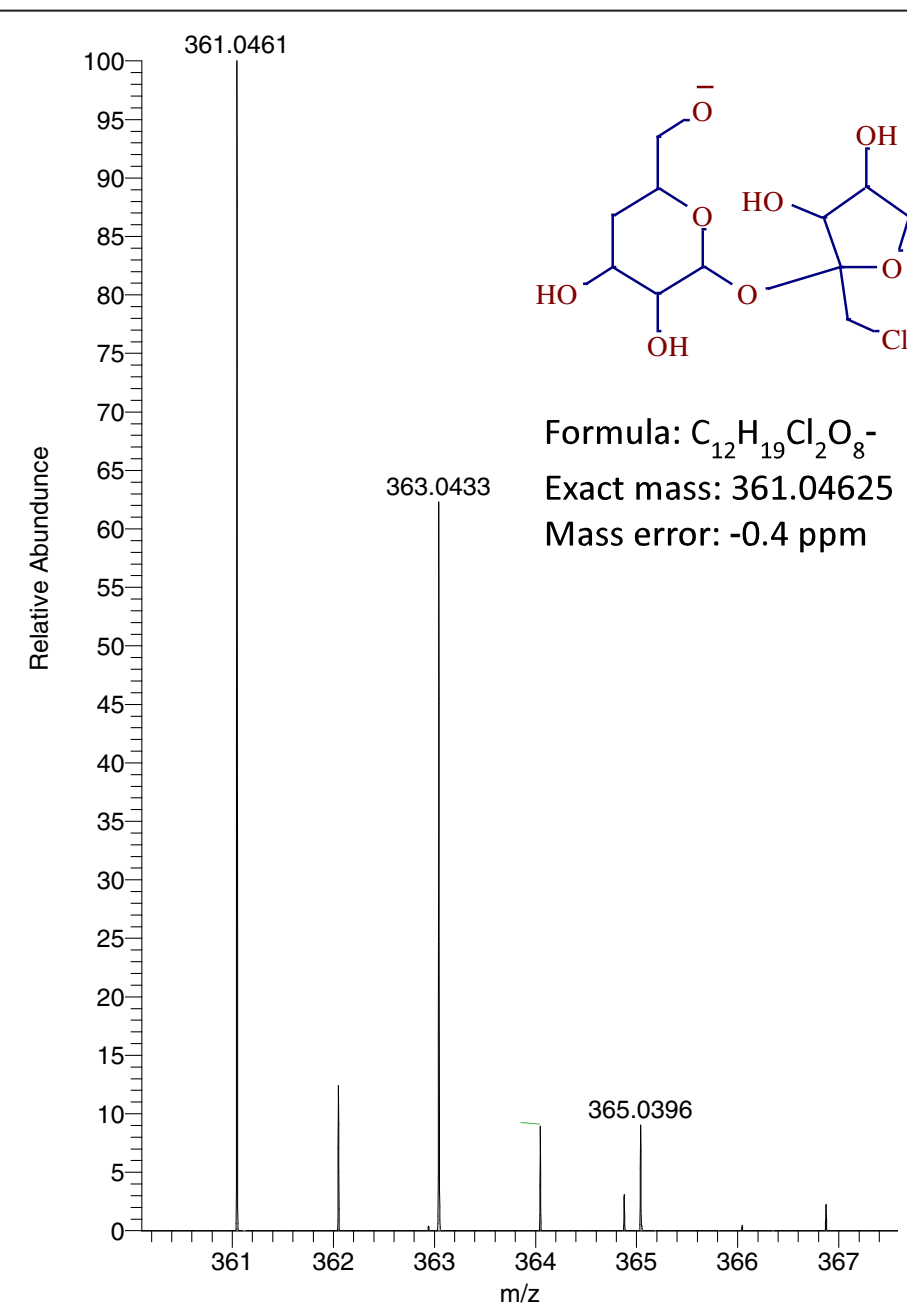

Figure 5 Chlorine isotopic pattern of sucralose photolysis product detected in negative ionization mode. 
was produced, making it impossible to obtain any structural information on the photodegradation product. Alternately, Full scan and MS/MS experiments were performed using in-source collision induced dissociation (CID), which will fragment all ions after the first quadrupole. The sample was run in the full scan mode $(\mathrm{m} / \mathrm{z} 100-500)$ with 3 different CIDs i.e. 0,15 and $25 \mathrm{eV}$ while monitoring the decrease of the parent ion (m/z 395.0072) and the increase of the photo-product $(\mathrm{m} / \mathrm{z}$ 361.0463) and their formate adduct ions intensity ( $\mathrm{m} / \mathrm{z} 441.0130$ and 407.0518). When the CID was increased from 0 to $15 \mathrm{eV}$, the abundance of both formate adduct ions decreased while the intensity of $\mathrm{m} / \mathrm{z} 395.0072$ and $\mathrm{m} / \mathrm{z} 361.0463$ increased. However, when the CID was ramped to $25 \mathrm{eV}$, the intensity of all formed ions decreased.
The same samples were then run in the positive ionization (PI) mode with same source and mobile phase conditions. Sucralose was detected in PI mode as the sodium adduct at $\mathrm{m} / \mathrm{z} 419.0045$, which is in good agreement with the results shown by Ferrer et al. 2010 [5]. However, the sensitivity in PI mode was 10-20 fold lower than in negative mode. The photolysis product identified at $4.4 \mathrm{~min}$ in negative mode was also identified in PI mode at the same retention time, but as a sodiated molecule at $\mathrm{m} / \mathrm{z}$ 385.0428. This structure is produced by the loss of one chlorine from sucralose and corresponds to the molecular formula $\mathrm{C}_{12} \mathrm{H}_{20} \mathrm{Cl}_{2} \mathrm{NaO}_{8}^{+}$(+0.25 ppm). The chromatograms of sucralose and its photolysis product in PI mode are shown in Figure 6. The HRMS spectrum of the photolysis product obtained at 35,000 resolution displayed the

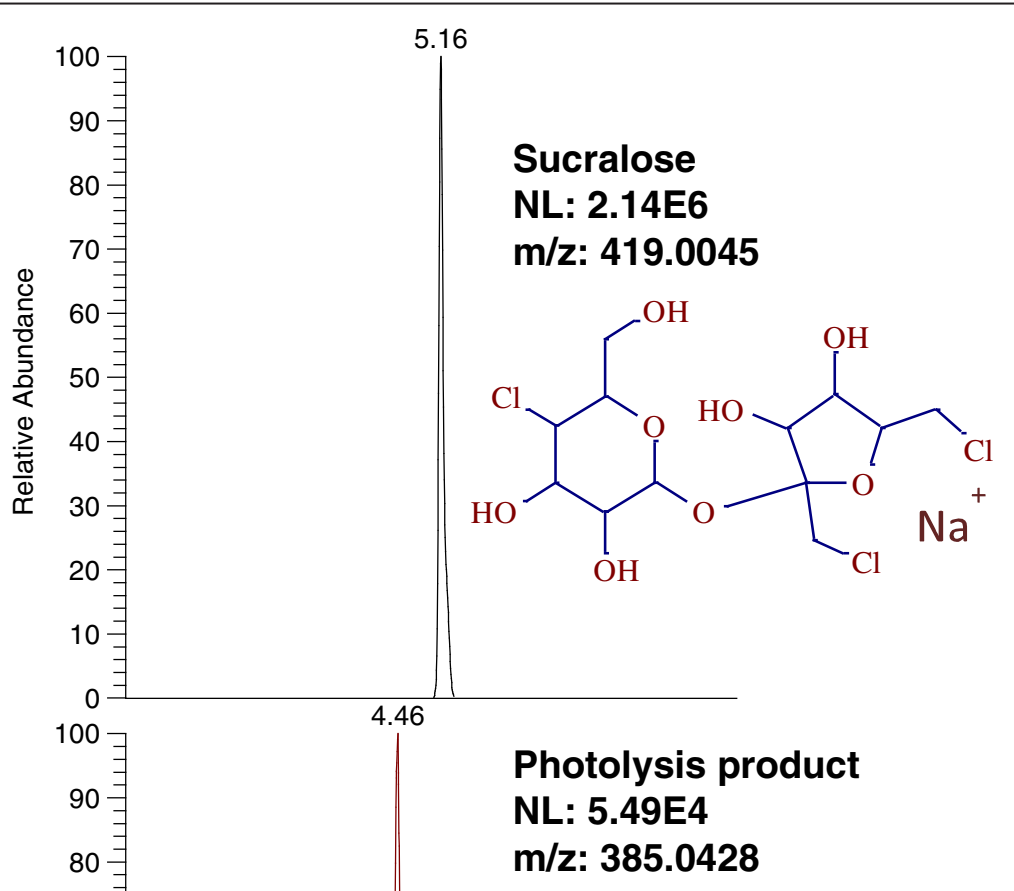

Figure 6 LC-MS chromatograms of sucralose and its photolysis product in positive ionization mode. 


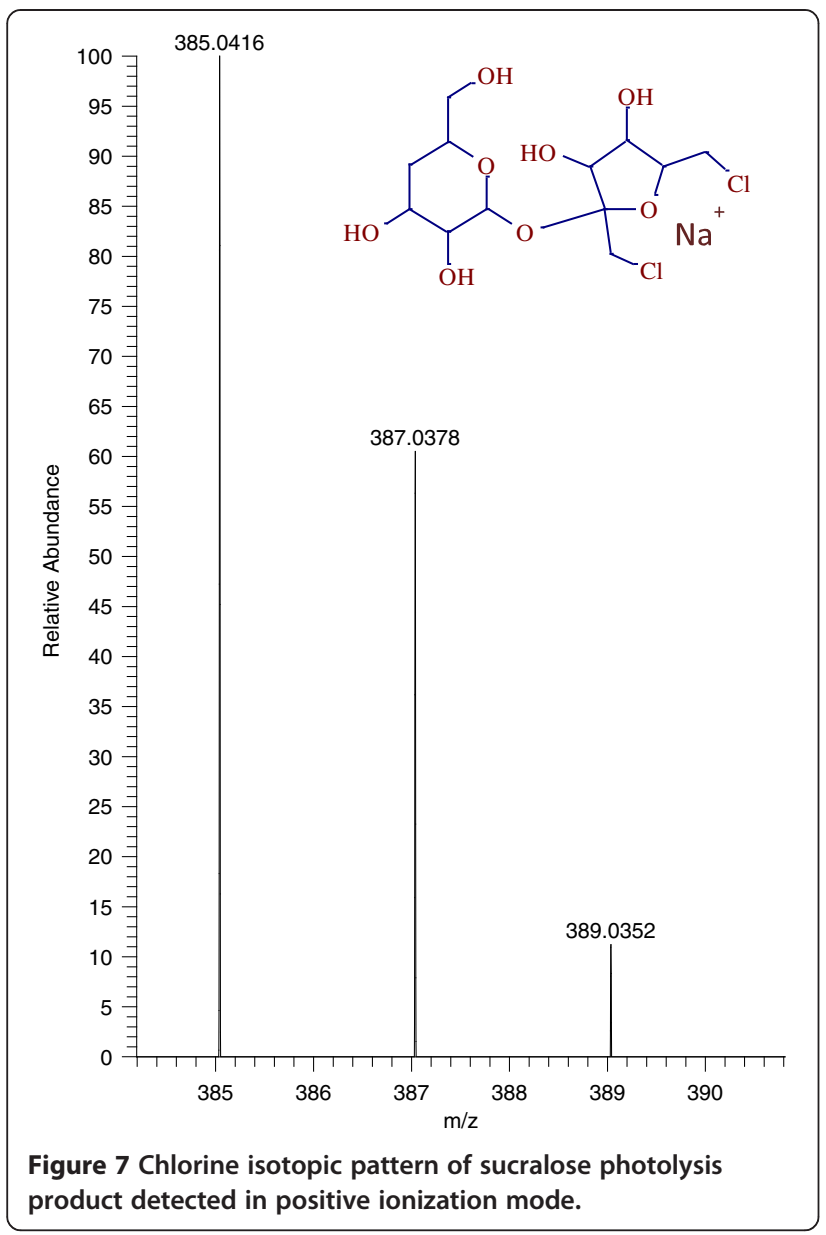

product detected in positive ionization mode. characteristic chlorine isotopic pattern consistent with the parent molecule and is shown in Figure 7.

MS/MS information on the photolysis product was obtained at 20\% NCE with an isolation window of $1 \mathrm{~m} / \mathrm{z}$ and is used to elucidate the possible structure out of 3 possible ones (A, B or C) (Figure 8).

The major MS/MS fragment at $\mathrm{m} / \mathrm{z} 238.9842$ with relative abundance of $70 \%$, indicates that the Structure $\mathrm{A}$ is the most possible photodegradation product of sucralose. The MS/MS spectrum of the photolysis product, $\mathrm{m} / \mathrm{z} 385.0428$ with estimated mass errors on parent and fragments is presented in Figure 9. Chlorine isotopic pattern on MS/MS fragments was not observed due to the small isolation window selected on the parent ion ( $\mathrm{m} / \mathrm{z}$ 385.0428). Reclaimed water with positive detection of sucralose was run using the same method and the photo transformation product was not detected, suggesting that dechlorination of sucralose is not a preferred metabolic reaction and will occur only under prolonged UV irradiation.

\section{Conclusion}

An automated online SPE LC-APCI/MS/MS was developed and validated for the determination of sucralose at low $\mathrm{ng} / \mathrm{L}$ levels in water samples. The method was successfully applied to drinking and reclaimed waters from South Florida, U.S.A. The method detection limits were $8.5 \mathrm{ng} / \mathrm{L}$ and $2.7 \mu \mathrm{g} / \mathrm{L}$ in drinking and reclaimed waters, respectively. In all matrices tested, the recovery of sucralose ranged from $85-113 \%$. Sucralose was frequently detected (> 80\%) in all studied samples with concentrations as high as $18 \mu \mathrm{g} / \mathrm{L}$. The mass load per capita of sucralose released by the WWTP effluent by taking into consideration all the studies published to date was estimated as $5.0 \mathrm{mg} /$ day/person in the U.S. and is two times higher than the global and European Union. The maximum<smiles>CCC1(CCl)OC(CCl)C(O)C1OC1OC(CO)C(Cl)C(O)C1OC1(CCl)OC(CO)C(O)C1OC1OC(CO)C(O)C(O)C1OC1(CCl)OC(C)C(O)C1O</smiles>

Figure 8 Possible structures for the sucralose photolysis product. 

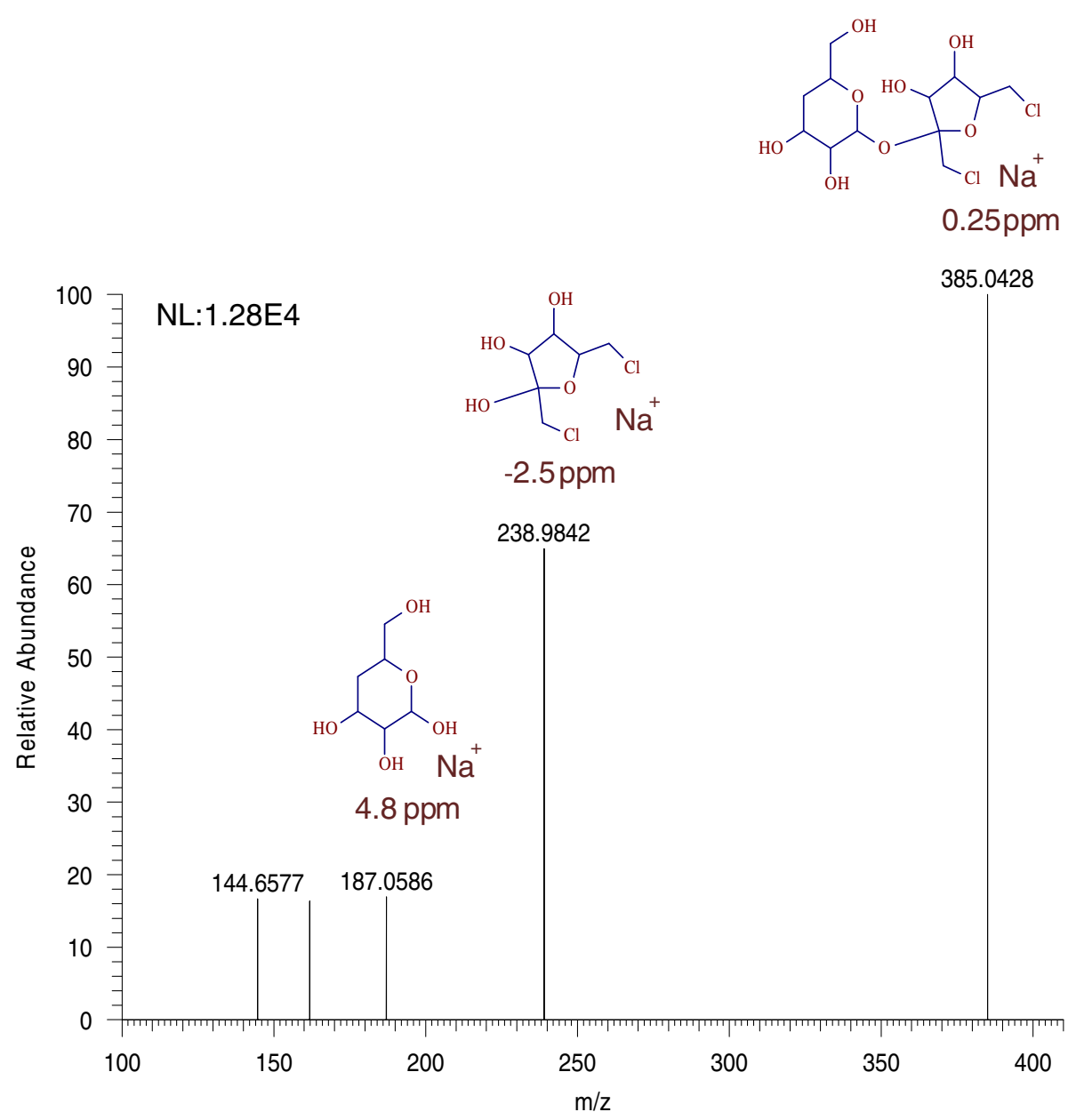

Figure 9 LC-MS/MS HRMS spectrum of sodiated photolysis product, m/z 385.0428 .

concentration of sucralose detected in drinking waters was $465 \mathrm{ng} / \mathrm{L}$. Based on a study conducted by Fujimaru et al. it has been estimated that $79.5 \mathrm{mg}$ of sucralose is required to make $1 \mathrm{~L}$ of water weakly sweet [54]. Thus, considering the calculated global mass load of sucralose discharged by the WWTPs it would still take $8.43 . \mathrm{E}+13$ years to make the ocean waters become sweet. The ubiquitousness of sucralose in the aquatic environment is however of great concern, especially since little information is known to date about its potential long term ecological effects. Photodegradation of sucralose was minimal at environmental relevant conditions. Its high resistance to photodegradation, minimal sorption and high solubility could explain the high frequency of detection and levels found in this and other studies. These results corroborate with previous findings indicating that sucralose could be a good tracer of anthropogenic wastewater intrusions into the environment. The new photolysis product identified in this study is likely produced by the loss of a chlorine directly from sucralose. To our best knowledge this is the first time that a photodegradation product of sucralose was identified.

\section{Additional files}

Additional file 1: Figure S1. Structure of sucralose. Figure S2. Comparison of emission spectrum of a group of $254 \mathrm{~nm}$ light source, $350 \mathrm{~nm}$ light source and Sun Test versus natural sun light. Figure S3. LC-MS water fortified with sucralose at $200 \mathrm{ng} / \mathrm{L}$ (top) LC-MS water fortified with sucralose-d6 (internal standard) at $50 \mu \mathrm{g} / \mathrm{L}$ (bottom). $0.1 \%$ formic acid in LC-MS grade water was used as modifier. Table S1. Characteristics of canal water and sea water used in the experiment.

Additional file 2: Table S2. Gradient program for sucralose determination in drinking and reclaimed water. Top left: loading pump gradient for drinking waters, top right: loading pump gradient for reclaimed waters, bottom left: analytical pump gradient for drinking waters, bottom right: analytical pump gradient for reclaimed waters.

Competing interests

The authors declare that they have no competing interests.

\section{Authors' contributions}

BSR developed the online SPE-LC-MS/MS method, analyzed reclaimed waters, performed photodegradation experiments and identified photolysis products in high resolution mass spectrometry. NSQ developed direct injection LC-MS/MS method, collaborated with PVR in optimizing the method for the analysis of sucralose in drinking waters. PVR collected both reclaimed and drinking waters and trained BSR to use metabolic profiling 
software (Metworks). BSR, NSQ and PVR prepared and revised the manuscript. PRG procured funding, supervised the research and revised the final manuscript for publication. All the authors read and approved the final manuscript.

\section{Acknowledgements}

The Environmental Analysis Research Laboratory acknowledges the support from the Thermo Scientific Corporation in the development of this work. Sudha Rani Batchu would like to thank Florida International University graduate school for supporting her through Doctoral Evidence Acquisition Fellowship. This is SERC contribution 636

Received: 26 June 2013 Accepted: 15 August 2013

Published: 22 August 2013

\section{References}

1. Brorström-Lundén E, Svenson A, Viktor T, Woldegiorgis A, Remberger M, Kaj L, Dye C, Bjerke A, Schlabach M: Measurements of Sucralose in the Swedish Screening Program 2007-PART 1; Sucralose in surface waters and STP samples IVL B1769. Stockholm: IVL Swedish Environmental Research Institute Ltd; 2008.

2. Mead RN, Morgan JB, Avery GB Jr, Kieber RJ, Kirk AM, Skrabal SA, Willey JD: Occurrence of the artificial sweetener sucralose in coastal and marine waters of the United States. Mar Chem 2009, 116:13-17.

3. Loos R, Gawlik BM, Boettcher K, Locoro G, Contini S, Bidoglio G: Sucralose screening in European surface waters using a solid-phase extractionliquid chromatography-triple quadrupole mass spectrometry method. J Chromatogr A 2009, 1216:1126-1131.

4. Scheurer M, Brauch H-J, Lange FT: Analysis and occurrence of seven artificial sweeteners in German waste water and surface water and in soil aquifer treatment (SAT). Anal Bioanal Chem 2009, 394:1585-1594.

5. Ferrer I, Thurman EM: Analysis of sucralose and other sweeteners in water and beverage samples by liquid chromatography/time-of-flight mass spectrometry. J Chromatogr A 2010, 1217:4127-4134.

6. Mawhinney DB, Young RB, Vanderford BJ, Borch T, Snyder SA: Artificial Sweetener Sucralose in U.S. Drinking Water Systems. Environ Sci Technol 2011, 45:8716-8722.

7. Brown KD, Kulis J, Thomson B, Chapman TH, Mawhinney DB: Occurrence of antibiotics in hospital, residential, and dairy, effluent, municipal wastewater, and the Rio Grande in New Mexico. Sci Total Environ 2006 366:772-783.

8. Minten J, Adolfsson-Erici M, Bjorlenius B, Alsberg T: A method for the analysis of sucralose with electrospray LC/MS in recipient waters and in sewage effluent subjected to tertiary treatment technologies. Int J Environ Anal Chem 2011, 91:357-366.

9. Oppenheimer J, Eaton A, Badruzzaman M, Haghani AW, Jacangelo JG: Occurrence and suitability of sucralose as an indicator compound of wastewater loading to surface waters in urbanized regions. Water Res 2011, 45:4019-4027.

10. Grice HC, Goldsmith LA: Sucralose - An overview of the toxicity data. Food Chem Toxicol 2000, 38:1-6.

11. Lubick N: Artificial sweetener persists in the environment. Environ Sci Technol 2008, 42:3125-3125.

12. Wiklund A-KE, Breitholtz M, Bengtsson B-E, Adolfsson-Erici M: Sucralose - An ecotoxicological challenger? Chemosphere 2012, 86:50-55.

13. Soh L, Connors KA, Brooks BW, Zimmerman J: Fate of Sucralose through Environmental and Water Treatment Processes and Impact on Plant Indicator Species. Environ Sci Technol 2011, 45:1363-1369.

14. Hjorth M, Hansen JH, Camus L: Short-term effects of sucralose on Calanus finmarchicus and Calanus glacialis in Disko Bay, Greenland. Chem Ecol 2010, 26:385-393.

15. Lillicrap A, Langford K, Tollefsen KE: Bioconcentration of the intense sweetener sucralose in a multitrophic battery of aquatic organisms. Environ Toxicol Chem 2011, 30:673-681.

16. Lappin-Scott HM, Holt G, Bull AT: Microbial transformation of 1,6-dichloro-1,6dideoxy- $\beta$, D-fructofuranosyl-4-chloro-4-deoxy-a, D-galactopyranoside (TGS) by soil populations. MIRCEN J Appl Microb 1987, 3:95-102.

17. Labare MP, Alexander M: Microbial cometabolism of sucralose, a chlorinated discaccharide, in environmental-samples. Appl Microbiol Biotechnol 1994, 42:173-178.
18. Labare MP, Alexander M: Biodegradation of sucralose, a chlorinated carbohydrate, in samples of natural environments. Environ Toxicol Chem 1993, 12:797-804.

19. Lange FT, Scheurer M, Brauch HJ: Artificial sweeteners-a recently recognized class of emerging environmental contaminants: a review. Anal Bioanal Chem 2012, 403:2503-2518.

20. Buerge IJ, Buser H-R, Kahle M, Mueller MD, Poiger T: Ubiquitous Occurrence of the Artificial Sweetener Acesulfame in the Aquatic Environment: An Ideal Chemical Marker of Domestic Wastewater in Groundwater. Environ Sci Technol 2009, 43:4381-4385.

21. Torres Cl, Ramakrishna S, Chiu C-A, Nelson KG, Westerhoff P, KrajmalnikBrown R: Fate of sucralose during wastewater treatment. Environ Eng Sci 2011, 28:325-331.

22. Ordonez EY, Benito Quintana J, Rodil R, Cela R: Determination of artificial sweeteners in water samples by solid-phase extraction and liquid chromatography-tandem mass spectrometry. J Chromatogr A 2012, 1256:197-205.

23. Panditi VR, Batchu SR, Gardinali PR: Online solid phase extraction-liquid chromatography-electrospray-tandem mass spectrometric determination of multiple classes of antibiotics in environmental and treated waters. Anal Bioanal Chem 2013, 405:5953-5964.

24. Quinete N, Wang J, Fernandez A, Castro J, Gardinali PR: Outcompeting GC for the detection of legacy chlorinated pesticides: online-SPE UPLC APCI/ MSMS detection of endosulfans at part per trillion levels. Anal Bioanal Chem. 2013, 405:5887-5899.

25. Neset TSS, Singer $H$, Longree $P$, Bader HP, Scheidegger R, Wittmer A Andersson JCM: Understanding consumption-related sucralose emissions A conceptual approach combining substance-flow analysis with sampling analysis. Sci Total Environ 2010, 408:3261-3269.

26. Heeb F, Singer H, Pernet-Coudrier B, Qi WX, Liu HJ, Longree P, Muller B, Berg M: Organic Micropollutants in Rivers Downstream of the Megacity Beijing: Sources and Mass Fluxes in a Large-Scale Wastewater Irrigation System. Environ Sci Technol 2012, 46:8680-8688.

27. Ramirez CE, Batchu SR, Gardinali PR: High sensitivity Liquid Chromatography Tandem Mass Spectrometric (LC-MS/MS) methods for the analysis of dioctyl sulfosuccinate (DOSS) in different stages of an oil spill response monitoring effort. Anal Bioanal Chem 2013, 405:4167-4175.

28. Zaikin VG, Halket JM: Derivatization in mass spectrometry - 8. Soft ionization mass spectrometry of small molecules. Eur J Mass Spectrom 2006, 12:79-115.

29. Singh G, Gutierrez A, Xu KY, Blair IA: Liquid chromatography/electron capture atmospheric pressure chemical ionization/mass spectrometry: Analysis of pentafluorobenzyl derivatives of biomolecules and drugs in the attomole range. Anal Chem 2000, 72:3007-3013.

30. Thurman EM, Ferrer I, Barcelo D: Choosing between atmospheric pressure chemical ionization and electrospray ionization interfaces for the HPLC/ MS analysis of pesticides. Anal Chem 2001, 73:5441-5449.

31. Chusaksri S, Sutthivaiyakit S, Sutthivaiyakit P: Confirmatory determination of organochlorine pesticides in surface waters using $\mathrm{LC} / \mathrm{APCl} /$ tandem mass spectrometry. Anal Bioanal Chem 2006, 384:1236-1245.

32. Maragou NC, Thomaidis NS, Koupparis MA: Optimization and Comparison of ESI and APCI LC-MS/MS Methods: A Case Study of Irgarol 1051, Diuron, and their Degradation Products in Environmental Samples. J Am Soc Mass Spectrom 2011, 22:1826-1838.

33. King R, Bonfiglio R, Fernandez-Metzler C, Miller-Stein C, Olah T: Mechanistic investigation of ionization suppression in electrospray ionization. J Am Soc Mass Spectrom 2000, 11:942-950.

34. Levine $A D$, Asano $T$ : Recovering sustainable water from wastewater. Environ Sci Technol 2004, 38:201A-208A.

35. Miamidade: About reclaimed water; 2013. http://www.miamidade.gov/water/ reclaimed-water-about.asp. Accessed on 7/10/2013.

36. MDWASD: Alternative water supply plan and reuse feasibility plan annual progress report. http://www.miamidade.gov/water/library/reports/water-usepermit-alternative-supply-reuse-2007.pdf. Accessed on 10/1/2012; 2007.

37. Panditi VR: Assessment of the Occurrence and Potential Risks of Antibiotics and their Metabolites in South Florida Waters Using Liquid Chromatography Tandem Mass Spectrometry. 2013. FIU Electronic Theses and Dissertations. Paper 916. http://digitalcommons. fiu.edu/etd/916. 
38. Fernandez M, Pico Y, Manes J: Comparison of gas and liquid chromatography coupled to mass spectrometry for the residue analysis of pesticides in oranges. Chromatographia 2001, 54:302-308.

39. Radjenovic J, Godehardt M, Petrovic M, Hein A, Farre M, Jekel M, Barcelo D: Evidencing Generation of Persistent Ozonation Products of Antibiotics Roxithromycin and Trimethoprim. Environ Sci Technol 2009, 43:6808-6815.

40. Li DHW, Lam JC, Lau CCS: A Study of Solar Radiation Daylight Illuminance and Sky Luminance Data Measurements for Hong Kong. Archit Sci Rev 2002, 45:21-30.

41. Diepens M, Gijsman P: Photodegradation of bisphenol A polycarbonate. Polym Degrad Stab 2007, 92:397-406.

42. Wu ZR, Gao WQ, Phelps MA, Wu D, Miller DD, Dalton JT: Favorable effects of weak acids on negative-ion electrospray ionization mass spectrometry. Anal Chem 2004, 76:839-847.

43. USEPA: Definition and procedures for the determination of the method detection limit. Revision 1.11. edition. Guidelines establishing test procedures for the analysis of pollutants. Appendix B, part 136. Definition and procedures for the determination of the method detection limit. U.S. Code of Federal Regulations, Title 40. Revision 1.11; 2010.

44. USCB: State \& County QuickFacts; 2011. http://quickfacts.census.gov/qfd/ states/12/1249450.html. Accessed on 10/1/2012.

45. Scheurer M, Storck FR, Graf C, Brauch HJ, Ruck W, Lev O, Lange FT: Correlation of six anthropogenic markers in wastewater, surface water, bank filtrate, and soil aquifer treatment. J Environ Monit 2011, 13:966-973.

46. Brorstrom-Lunden E, Svensson A, Viktor T, Woldegiorgis A, Remberger M Kaj L, Dye C, Bjerke A, Schlabach M: Measurements of Sucralose in the Swedish Screening program 2007. Part 2; Sucralose in Biota samples and regional STP samples. Sweden: IVL Swedish Environmental Research Institute Ltd, Stockholm; 2008.

47. Morlock GE, Schuele L, Grashorn S: Development of a quantitative highperformance thin-layer chromatographic method for sucralose in sewage effluent, surface water, and drinking water. J Chromatogr A 2011, 1218:2745-2753.

48. Berset JD, Ochsenbein N: Stability considerations of aspartame in the direct analysis of artificial sweeteners in water samples using high-performance liquid chromatography-tandem mass spectrometry (HPLC-MS/MS). Chemosphere 2012, 88:563-569.

49. Gan Z, Sun H, Wang R, Feng B: A novel solid-phase extraction for the concentration of sweeteners in water and analysis by ion-pair liquid chromatography-triple quadrupole mass spectrometry. J Chromatogr A 2013, 1274:87-96.

50. Imhoff K, Imhoff K: Taschenbuch der Stadtentwässerung (Pocketbook on Sewerage). 26th edition. Munich: R. Oldenbourg; 1985.

51. UNEP: International Source Book on Environmentally Sound Technologies for Wastewater and Stormwater Management; 2000. http://www.unep.or.jp/letc/ Publications/TechPublications/TechPub-15/main_index.asp. Accessed on 2/ 20/2013.

52. Water supply \& Treatment. http://www.miamidade.gov/water/water-supplytreatment.asp. Accessed on 4/1/2013.

53. Scheurer M, Storck FR, Brauch H-J, Lange FT: Performance of conventional multi-barrier drinking water treatment plants for the removal of four artificial sweeteners. Water Res 2010, 44:3573-3584.

54. Fujimaru T, Park JH, Lim J: Sensory Characteristics and Relative Sweetness of Tagatose and Other Sweeteners. J Food Sci 2012, 77:S323-S328.

Cite this article as: Batchu et al.: Online solid phase extraction liquid chromatography tandem mass spectrometry (SPE-LC-MS/MS) method for the determination of sucralose in reclaimed and drinking waters and its photo degradation in natural waters from South Florida. Chemistry Central Journal 2013 7:141.

\section{Publish with ChemistryCentral and every scientist can read your work free of charge \\ "Open access provides opportunities to our colleagues in other parts of the globe, by allowing anyone to view the content free of charge." \\ W. Jeffery Hurst, The Hershey Company. \\ - available free of charge to the entire scientific community \\ - peer reviewed and published immediately upon acceptance \\ - cited in PubMed and archived on PubMed Central \\ - yours - you keep the copyright \\ Submit your manuscript here: \\ http://www.chemistrycentral.com/manuscript/<smiles>c1ccccc1</smiles> \\ Chemistry Central}

